\title{
A Comparison of Demographics, Disease Activity, Disability, and Treatment Among Rheumatoid Arthritis Patients with and without Osteoporosis
}

\author{
Altaf Abdulkhaliq (D) \\ Mohamed Cheikh (D) ${ }^{2,3}$ \\ Fahad Almuntashri (iD) \\ Haneen Alzahrani ${ }^{4}$ \\ Huda Nadwi (iD ${ }^{4}$ \\ Eithar Kadi (iD) ${ }^{4}$ \\ Mutasem Abed (iD) \\ Murad Janaini $\mathbb{D}^{4}$ \\ Alaa Monjed ${ }^{4}$ \\ Nahed Janoudi ${ }^{2}$ \\ Hani Almoallim (D) ${ }^{4,5}$
}

'Department of Clinical Biochemistry, Faculty of Medicine, Umm Al Qura

University, Makkah, Saudi Arabia;

${ }^{2}$ Internal Medicine Department, Doctor

Soliman Fakeeh Hospital, Jeddah, Saudi

Arabia; ${ }^{3}$ Department of Medicine, Fakeeh College for Medical Sciences, Jeddah, Saudi Arabia; ${ }^{4}$ Department of Medicine, Faculty of Medicine, Umm Al Qura University, Makkah, Saudi Arabia; ${ }^{5}$ Alzaidi Chair of Research in Rheumatic Diseases, Umm Al Qura University, Makkah, Saudi Arabia
Correspondence: Fahad Almuntashri Tel +966542626003

Email fahadalmuntashri@gmail.com
Introduction: Osteoporosis (OP) is one of the most common comorbidities associated with rheumatoid arthritis (RA). Literatures reported that the risk for developing OP was strongly associated with duration and severity of RA. We aim to elaborate on the consequences of OP on disease activity and management plan in patients with RA.

Patients and Methods: A retrospective cohort study recruited 408 patients, including those with RA alone and with RA plus OP. The RA disease activity in the patients was assessed using disease activity score in 28 joints (DAS28-CRP). A statistical analysis was performed to compare data between the two groups of patients and determine any significant risk factor associated with the development of OP in RA patients.

Results: Of 408 patients who were included in this study, 353 patients ( $86.5 \%)$ had only RA, while 55 patients $(13.5 \%)$ had RA with OP and showed significant difference $(P=0.04)$ concerning age categories. Patients diagnosed with RA and OP had RA duration longer than RA-only patients (independent $t$-test, $P=0.01$ ). The two groups had almost similar disease activity at the three clinical visits, as well, had nearly similar disability at their first visit, whereas RA with OP patients had significant greater disability at their $2^{\text {nd }}$ and $3^{\text {rd }}$ visits (independent $t$-test, $P=0.001$ ). Both groups were treated with the same biologic and nonbiologic medication of similar frequency, although RA patients with OP received steroid more frequently than patients had RA only $(61.7 \%$ vs. $41.7 \%$, chi square test, $P=0.03)$.

Conclusion: There was no significant difference in disease activity at both groups of patients. However, RA with OP group had longer duration of RA, were more frequently treated with steroids, and had greater disability. We recommend physicians focus on controlling RA disease activity, early screening for and treating of OP.

Keywords: rheumatoid arthritis, osteoporosis, disease activity, biologic, disease modifying antirheumatic drugs, effects, RA OP

\section{Introduction}

Generally, the rheumatic diseases are characterized by local and systemic bone loss that has multifactorial basis including direct effects of inflammatory process (disease activity), inadequate nutrition, decreased lean body mass, immobility, and the effects of therapeutic agents, namely glucocorticoids (GC). ${ }^{1}$ Among these rheumatic diseases is rheumatoid arthritis (RA), a chronic inflammatory autoimmune disease of the joints that is associated with disabilities and multiple comorbidities including osteoporosis (OP), called secondary $\mathrm{OP}^{2}$ OP can be defined as a decreased bone mineral density (BMD) due to imbalance in bone remodeling 
cycle, where the rate of bone resorption exceeds bone formation, leading to microarchitectural deterioration that ultimately causes frail bones and susceptibility to fracture. $^{1,3}$ Very recently, Almutairi et al conducted a meta-analysis study based on systematic reviews to estimate the global prevalence of RA that appeared to be $0.46 \%$ with a $95 \%$ prediction interval $(0.06-1.27 \%){ }^{4}$ Multiple studies showed that OP occurred in $30-50 \%$ of RA patients, ${ }^{5-7}$ where the risk for developing OP was strongly associated with duration and severity of the disease, in addition to the age and gender of the patients. ${ }^{8,9}$ Therefore, pre-menopausal women with RA are two times more susceptible to have OP and bone fractures compared to age-matched healthy controls, ${ }^{10}$ and so are male individuals with RA. ${ }^{11}$

In $\mathrm{RA}$, the earliest radiological sign of bone destruction is the periarticular osteopenia, which is mainly associated with disease activity, and then followed by bone erosion that indicates increasing disease activity and disability of the disease. ${ }^{1}$ Likewise periarticular bone loss, citrullinated proteins antibodies (ACPA) are associated with systemic bone loss, with a titer-dependent effect on BMD. ${ }^{12}$ The further stage of markedly bone loss in RA is the development of OP. ${ }^{1}$ The development of OP in patients with RA elaborates on the interplay between the cells of the immune system with those involved in the regulation of bone remodeling, in particular via receptor activator of the nuclear factor kappa-B ligand (RANKL)/osteoprotegerin (OPG) system and WNT/ß-catenin signaling pathways. RANKL is a cytokine of the tumor necrosis factor (TNF) family and, with its decoy molecule OPG, is essential for osteoclast maturation and development. ${ }^{13}$ On the other hand, the WNT/ß-catenin signaling pathway activates the transcription of osteoblast-specific genes that enhances osteoblast differentiation and is considered as a major regulator of osteogenesis. ${ }^{14}$

The underlying pathology for developing the active disease in RA can be explained by the imbalance in the immune system (including the inflammatory cells and the released cytokines) that alter bone remodeling via inhibition of osteoblast differentiation, and induction of osteoclast differentiation and hence the net result is bone resorption leading to secondary OP. Accordingly, during disease activity, Th1 and Th17 cells produce the proinflammatory cytokines that have a significant role in the inflammatory and bone destruction processes. Of these cytokines, TNF- $\alpha$, IL-1b, IL-6, IL-11, and IL-17 have stimulatory effects either directly on osteoclast differentiation and activation, or indirectly by enhancing cell surface expression of RANKL that stimulate osteoclastogenesis. ${ }^{15}$ Moreover, TNF- $\alpha$ can induce the Wnt-signaling inhibitors, sclerostin and Dickkopf-related protein-1 (Dkk-1), leading to inhibition of osteoblastic differentiation. ${ }^{16}$ In the contrary, the inhibitory cytokines including interferon (IFN)- $\gamma$, IL-4, and transforming growth factor- $\beta$ (TGF- $\beta$ ) inhibit the expression of OPG on osteoblast. ${ }^{14}$ Dkk-1 is a key regulator of joint remodeling in $\mathrm{RA}^{17}$ that was found to be significantly elevated in RA patients in a 2018 meta-analysis on 1305 patients and 504 controls. ${ }^{18}$ It has been reported that the OPG/RANKL ratio was lower in patients with active RA than in healthy controls, while Dkk-1 was higher in those patients. ${ }^{19}$ However, following the treatment with anti-IL-6, the OPG/RANKL ratio started to increase, while Dkk-1 decreased. ${ }^{19}$ Therefore, OP is an inevitable complication of RA, and despite the alarming data of the prevalence of OP among patients with RA, only about $45 \%$ of RA patients are receiving calcium and vitamin D supplements, ${ }^{20}$ while only $5.4 \%$ of RA patients who are not taking glucocorticoids (GCs) are using bisphosphonates. ${ }^{21}$ Adding to that, due to the subsequent negative impacts of OP on the quality of life of patients with RA, early prevention, diagnosis, and further proper treatment of OP is mandatory, as well as, controlling RA disease activity is important as this treatment can have anti-osteoporotic effects.

Clearly, OP can develop in RA patients through different mechanisms including RA itself as briefly explained, the use of GCs and simply as a post-menopausal state due to estrogen deficiency. In the current study, we proposed that OP in patients with RA has a negative consequence on disease activity and thus may worsen the prognosis of RA. Therefore, a statistical comparison was conducted on a retrospective cohort of two groups of patients, the RAonly (RA without OP) patients and the RA-OP (RA with OP) patients to elaborate on the effects of OP on disease activity, patients' outcomes, and management plan.

\section{Patients and Methods}

This retrospective cohort study was conducted at Doctor Soliman Fakeeh Hospital (DSFH), a private, tertiary hospital in Saudi Arabia's western region. DSFH employs one full- and two half-time rheumatology consultants to evaluate and treat patients. Medical records of 408 patients with RA following up in the clinics from May 2018 to August 2020 were reviewed from the Saudi registry of the 
Rheumatoid Arthritis Saudi Database (RASD). The inclusion criteria of the study defined as adult patients $(\geq 18$ years) with the diagnosis of RA-only and RA plus OP (RA-OP). The diagnosis of OP was confirmed in the patients by scoring the BMD that was measured by dualenergy X-ray absorptiometry (DEXA) scan and the request based on the treating physician clinical judgement. According to the WHO criteria. ${ }^{22}$ BMD showing T-score $<-2.5$ confirms the diagnosis of OP. However, glucocorticoid-induced OP (GIOP) was confirmed in patients receiving GCs by having BMD of T-score $<-1.5$ and required therapeutic intervention, ${ }^{23}$ as recommended by the American College of Rheumatology (ACR) criteria. ${ }^{24}$

This study was carried out longitudinally and all patients had three clinical visits for follow up with at least one clinical visit a year. The disease activity of RA in the patients was assessed using Disease Activity Score in 28 joints (DAS28) with C-reactive protein (CRP). ${ }^{25}$ Patients who did not complete DAS28-CRP full assessment, were lost to follow-up, or had missing data were excluded. The full description of inclusion criteria and follow up visit protocols were reported in detail in a previous RASD publication. ${ }^{26}$ All patients had signed individual consent forms before including their data in RASD. An ethical approval was obtained from the DSFHIRB. Our study is in full compliance with Declaration of Helsinki.

The primary objective of the study was to evaluate the impact of OP on RA disease activity in patients with RA using DAS28-CRP score. ${ }^{25}$ Remission was diagnosed in patients with a DAS28-CRP score $<2.6$, Low disease activity in patients with a DAS28-CRP score $\geq 2.6$ and $\leq 3.2$, Moderate disease activity with DAS28-CRP score $>3.2$ and $\leq 5.1$ and High disease activity in patients with a DAS28-CRP score $>5.1$. The secondary objective was to identify the significant association of various risk factors linked to the occurrence of OP among RA patients using a multivariable logistic regression analysis. The demographic and clinical variables referred in (Table 1) were investigated as risk factors for OP in RA patients

Table I Multivariable Logistic Regression Analysis of RA-Only Patients and RA-OP Patients Based on Demographics, Clinical Characteristics, and Treatment.

\begin{tabular}{|c|c|c|c|c|}
\hline \multirow[t]{2}{*}{ Variable } & \multirow[t]{2}{*}{ Odds Ratio } & \multirow[t]{2}{*}{ Sig. } & \multicolumn{2}{|c|}{ 95\% Confidence Interval of Odds Ratio } \\
\hline & & & Lower & Upper \\
\hline Age (years) & 0.952 & 0.036 & 0.909 & 0.997 \\
\hline Gender (Male) & 3.191 & 0.076 & 0.886 & 11.488 \\
\hline Gender (Female) & Reference group & & & \\
\hline Nationality (Saudi) & 1.949 & 0.181 & 0.733 & 5.181 \\
\hline Nationality (non-Saudi) & Reference group & & & \\
\hline Comorbidities* (yes) & 1.029 & 0.923 & 0.538 & 1.754 \\
\hline Comorbidities (No) & Reference group & & & \\
\hline DAS28 score Ist visit & 0.795 & 0.290 & 0.519 & 1.216 \\
\hline DAS28 score 2 nd visit & 1.940 & 0.058 & 0.978 & 3.849 \\
\hline DAS28 score 3rd visit & 0.784 & 0.550 & 0.354 & 1.739 \\
\hline On biological DMARDs (Yes) & 2.450 & 0.071 & 0.927 & 6.474 \\
\hline On biological DMARDs (No) & Reference group & & & \\
\hline On non-biological DMARDs (Yes) & 2.039 & 0.266 & 0.582 & 7.151 \\
\hline On non-biological DMARDs (No) & Reference group & & & \\
\hline Use of Steroid (Yes) ng/mL & 1.891 & 0.167 & 0.765 & 4.674 \\
\hline Vitamin D level (ng/mL) & 1.003 & 0.721 & 0.987 & 1.020 \\
\hline $\mathrm{BMI}$ & 0.987 & 0.741 & 0.915 & 1.065 \\
\hline RF positivity (YES) & 0.927 & 0.884 & 0.337 & 2.548 \\
\hline RF positivity (No) & Reference group & & & \\
\hline ACPA positivity (YES) & 0.510 & 0.194 & 0.185 & 1.409 \\
\hline ACPA positivity (No) & Reference group & & & \\
\hline CRP & 1.007 & 0.770 & 0.961 & 1.055 \\
\hline
\end{tabular}

Notes: The RA-only patients' group is the reference group. The control group is RA and OP. *Comorbidities include: Diabetes mellitus, Hypertension, and Chronic kidney disease. Abbreviations: DAS28-CRP, disease activity score in 28 joints; DMARDs, disease modifying anti-rheumatic drugs; BMI, body mass index; RF, rheumatoid factor; ACPA, anticitrullinated peptide antibody; CRP, C-reactive protein. 
and included age, gender, nationality, BMI, presence of comorbidity (namely diabetes mellitus, hypertension, or chronic kidney disease), DAS28-CRP score at each of three consecutive visits, biologic or non-biologic disease modifying antirheumatic drugs [DMARDs], steroid use, and laboratory investigations (vitamin D level, CRP, rheumatoid factor $[R F]$ positivity, and anti-citrullinated peptide antibodies [ACPA] positivity). DAS-28-CRP was calculated at each of the first 3 consecutive visits during the study period. Disability was measured by Health Assessment Questionnaire-Disability Index (HAQ-DI) ${ }^{27}$ at each of the first 3 consecutive visits during the study period. The HAQ-DI was scored as $0=$ without any difficulty, 1 = with some difficulty, 2 = much difficulty, and $3=$ unable to do.

\section{Statistical Analyses}

All data was analyzed by using the Statistical Package for Social science (IBM SPSS version 25) software program. Categorical variables were presented as the total and percentage, and continuous variables as the mean and standard deviation (SD). The chi-square test and Fisher's exact test for categorical variables and independent $t$-test for continuous variables were conducted to determine any associations between baseline characteristics, DAS28-CRP score (remission and low disease groups vs. moderate and high disease groups), and RA only versus RA with OP groups.

Logistic regression analysis with odds ratio was conducted to assess any significant associations between the explanatory variables (as the risk factors) and the dichotomous outcome of RA patients who were defined as the dependent variable whether they had $\mathrm{OP}$ or not. A $P$-value less than 0.05 was considered statistically significant for all tests.

\section{Results}

A total of 408 patients met the study criteria and were evaluated. Among them, $353(86.5 \%)$ patients had only RA, whereas 55 patients $(13.5 \%)$ had RA with OP (Table 2). There were no significant differences in both groups regarding the following demographics including gender, nationality, and body mass index (BMI), as well as the vitamin D status and the presence of comorbidities (DM, HTN, CKD). However, there is a significant difference $(P=0.04)$ at the age categories between the two groups of patients, where patients with RA plus OP showed older age than those with RA without OP (RA patients $46.3 \pm 10.3$ vs. RA patients with OP $64.8 \pm 10.8$ )
(Table 2). In addition, compared to RA-only patients, RAOP patients had a longer RA duration that showed significant difference $(79.5 \pm 52.5$ months vs. $106.6 \pm 62.6$ months respectively, independent $t$-test, $P=0.01$ ). Unexpectedly, RA patients with OP reported a smoking status less than patients with RA only ( $9.1 \%$ vs. $22.9 \%$, Chi square test, $P=0.01$ ) (Table 2).

On the other hand, the two clinical groups (RA-only and RA-OP patients) revealed similar disease activity at their all three clinical visits, based on DAS28-CRP score (Tables 2 and 3). Both groups of patients as well at the first clinical visit had similar disability that is measured by HAQ-DI. However, at the second and the third clinical visits, RA patients with OP had greater disability than RA patients without OP (Independent $t$-test, $P=0.001$ for both visit).

Multivariable logistic regression analyses were performed to identify potential risk factors associated with the occurrence of OP in RA patients (Table 1). These factors included gender, nationality, presence of comorbidities, DAS28-CRP score, types of DMARDs (biologics or non-biologics), use of steroid, vitamin D level, BMI measurement, positive RF and ACPA, and CRP level. Apparently, there were no significant differences in these risk factors between the two groups of patients.

In addition, the differences in therapeutic management of RA between RA-only patients and RA-OP patients were evaluated in term the type of biologic and non-biologic DMARDs and their frequency (Table 4). The results of descriptive analysis showed that both RA-only patients and RA-OP patients had received biologics with no significant differences between both groups (55.2\% vs. $43.6 \%$ respectively), and so did they with non-biologics DMARDs $(85.6 \%$ vs. $85.5 \%$ respectively) (Table 4$)$. The various biologic therapies that were prescribed including anti-TNF-alpha drugs (Adalimumab, Etanercept, Certolizumab), Janus kinase inhibitors drugs (Baricitinib and Tofacitinib), IL-6 receptor agonist (Tocilizumab), and anti-B cells therapy (Rituximab). The most type of biologics that had been used by RA-only patients was the antiTNF-alpha drugs (54.5\%) compared to (18.2\%) of RA-OP patients used anti-TNF-alpha therapy. On the other hand, the RA-OP patients received Janus kinase inhibitors drugs more frequently $(29.6 \%)$ than other biologic therapies. With regards the non-biologic DMARDs, the most frequent drugs used by both RA patients with and without OP was methotrexate $(33.1 \%$ vs. $46.8 \%)$ and showed no significant difference. 
Table 2 Demographic Characteristics of Study Patients

\begin{tabular}{|c|c|c|c|c|c|}
\hline \multicolumn{2}{|l|}{ Characteristics } & $\begin{array}{c}\text { All Patients } N=408 \\
(100 \%)\end{array}$ & $R A * * N=353(86.5 \%)$ & RA and $O P * * N=55$ (13.5\%) & P value* \\
\hline \multicolumn{3}{|l|}{ Age (years) } & $46.3 \pm 10.3$ & $64.8 \pm 10.8$ & 0.04 \\
\hline \multicolumn{3}{|l|}{ RA duration } & $79.5 \pm 52.5$ & $106.6 \pm 62.6$ & 0.01 \\
\hline \multicolumn{3}{|l|}{ OP duration } & - & $82.0 \pm 47.9$ & - \\
\hline Gender & $\begin{array}{l}\text { Male } \\
\text { Female }\end{array}$ & $\begin{array}{l}92(22.5) \\
316(77.5)\end{array}$ & $\begin{array}{c}83(23.5) \\
270(76.5)\end{array}$ & $\begin{array}{c}9(16.4) \\
46(83.6)\end{array}$ & 0.23 \\
\hline Nationality & $\begin{array}{l}\text { Saudi } \\
\text { Non-Saudi }\end{array}$ & $\begin{array}{l}255(62.7) \\
152(37.3)\end{array}$ & $\begin{array}{l}217(61.6) \\
135(38.4)\end{array}$ & $\begin{array}{l}38(69.1) \\
17(30.9)\end{array}$ & 0.28 \\
\hline Smoking status & $\begin{array}{l}\text { Smoker } \\
\text { Non-Smoker }\end{array}$ & $\begin{array}{c}86(21.1) \\
322(78.9)\end{array}$ & $\begin{array}{l}81(22.9) \\
272(77.1)\end{array}$ & $\begin{array}{c}5(9.1) \\
50(90.9)\end{array}$ & 0.01 \\
\hline Comorbidities*** & $\begin{array}{l}\text { Yes } \\
\text { No }\end{array}$ & $\begin{array}{l}262(64.2) \\
146(35.8)\end{array}$ & $\begin{array}{c}227(64.3) \\
126(35.7)\end{array}$ & $\begin{array}{l}35(63.6) \\
20(36.4)\end{array}$ & 0.92 \\
\hline BMI & $\begin{array}{l}\text { Underweight } \\
\text { Normal Weight } \\
\text { Overweight } \\
\text { Obese }\end{array}$ & $\begin{array}{c}3(0.7) \\
85(20.9) \\
108(26.6) \\
210(51.7)\end{array}$ & $\begin{array}{c}I(0.3) \\
74(21.1) \\
94(26.8) \\
182(51.9)\end{array}$ & $\begin{array}{c}2(3.6) \\
11(20.0) \\
14(25.5) \\
28(50.9)\end{array}$ & 0.20 \\
\hline \multicolumn{3}{|c|}{ Vitamin D level (ng/mL) } & $58.2 \pm 27.1$ & $55.8 \pm 26.0$ & 0.23 \\
\hline \multicolumn{2}{|l|}{ DAS28 score } & $\begin{array}{l}\text { Ist visit } \\
\text { 2nd visit } \\
\text { 3rd visit }\end{array}$ & $\begin{array}{l}3.00 \pm 0.98 \\
1.90 \pm 0.60 \\
1.68 \pm 0.51\end{array}$ & $\begin{array}{c}3.1 \pm 1.0 \\
2.13 \pm 0.56 \\
1.74 \pm 0.33\end{array}$ & $\begin{array}{l}0.52 \\
0.40 \\
0.42\end{array}$ \\
\hline \multicolumn{2}{|l|}{ HAQ- DI score } & $\begin{array}{l}\text { Ist visit } \\
\text { 2nd visit } \\
\text { 3rd visit }\end{array}$ & $\begin{array}{l}0.64 \pm 0.42 \\
0.28 \pm 0.25 \\
0.14 \pm 0.18\end{array}$ & $\begin{array}{l}0.79 \pm 0.41 \\
0.5 I \pm 0.33 \\
0.39 \pm 0.30\end{array}$ & $\begin{array}{l}0.68 \\
0.001 \\
0.001\end{array}$ \\
\hline
\end{tabular}

Notes: *P-value based on chi-square, Fisher exact test, or independent $t$-test as appropriate. ${ }^{* *} \mathrm{~N}(\%)$ and Mean \pm SD are presented as appropriate. $* * * C o m o r b i d i t i e s$ include: Diabetes mellitus, Hypertension, and Chronic kidney disease.

Abbreviations: RA, rheumatoid arthritis; OP, osteoporosis; BMI, body mass index; DAS28, disease activity score in 28 joints; HAQ -DI, Health Assessment QuestionnaireDisability Index.

Table 3 Disease Activity as Measured by DAS28 Score During the First 3 Clinic Visits in RA-only Patients and RA-OP Patients. Comparison of Patients with Remission \& Low Disease Activity to Those with Moderate \& High Disease Activity. Data Presented as Number and (\%)

\begin{tabular}{|c|c|c|c|c|c|}
\hline \multicolumn{2}{|l|}{ Characteristics } & \multirow{3}{*}{$\begin{array}{c}\text { All Patients } \mathbf{N}=\mathbf{4 0 8} \\
238(58.3) \\
170(4 \mid .7)\end{array}$} & \multirow{3}{*}{$\begin{array}{c}\text { RA N= } 353 \\
210(59.5) \\
143(40.5)\end{array}$} & \multirow{3}{*}{$\begin{array}{c}\text { RA and OP } \mathbf{N}=\mathbf{5 5} \\
28(50.9) \\
27(49.1)\end{array}$} & \multirow{3}{*}{$\frac{\text { P value** }}{0.23}$} \\
\hline DAS 28 score Ist visit & Remission \& Low disease activity & & & & \\
\hline & Moderate to High disease activity & & & & \\
\hline \multirow[t]{2}{*}{ DAS 28 score 2 nd visit } & Remission \& Low disease activity & $392(96.1)$ & $339(96.0)$ & $53(96.4)$ & 0.90 \\
\hline & Moderate to High disease activity & $16(3.9)$ & $14(4.0)$ & $2(3.6)$ & \\
\hline \multirow[t]{2}{*}{ DAS 28 score 3 rd visit } & Remission \& Low disease activity & $396(97.3)$ & $34 \mid(96.9)$ & $55(100)$ & 0.14 \\
\hline & Moderate to High disease activity & II (2.7) & II (3.I) & 0 & \\
\hline
\end{tabular}

Note: ** Chi-square or Fisher exact test as appropriate.

Abbreviations: RA, rheumatoid arthritis; OP, osteoporosis; DAS28, disease activity score in 28 joints.

In contrast to biologic and non-biologic medications, treatment with GCs revealed significant difference (Chi square test, $P=0.03$ ) between RA-only patients $(41.7 \%)$ compared to RA-OP patients (61.7\%). Finally, in addition to DMARDs, most patients having RA with OP (61.5\%) were receiving a RANK-ligand inhibitor (Denosumab) as 
Table 4 Types of Treatment Used by Diseased Groups. N(\%)

\begin{tabular}{|c|c|c|c|c|}
\hline Type of Treatment & & Only RA ( $N=353)$ & RA with OP $(\mathrm{N}=55)$ & P value* \\
\hline Biologic RA treatment received & $\begin{array}{l}\text { Yes } \\
\text { No }\end{array}$ & $\begin{array}{l}196(55.2) \\
157(44.8)\end{array}$ & $\begin{array}{l}24(43.6) \\
31(56.4)\end{array}$ & 0.11 \\
\hline Type of biological treatment & $\begin{array}{l}\text { Actemra§ } \\
\text { Baricitinib } \\
\text { Cimzia } \\
\text { Enbrel } \\
\text { Humira } \\
\text { Rituximab } \\
\text { Tofacitinib }\end{array}$ & $\begin{array}{l}26(I 3.3) \\
3(I .5) \\
23(I I .7) \\
4 I(20.9) \\
43(2 I .9) \\
4(2.0) \\
55(28.1)\end{array}$ & $\begin{array}{l}I(I .8) \\
I(I .8) \\
I(I .8) \\
3(5.5) \\
6(I 0.9) \\
2(3.6) \\
I 0(I 8.2)\end{array}$ & $\begin{array}{l}0.07 \\
0.25 \\
0.59 \\
0.48 \\
0.34 \\
0.68 \\
0.78\end{array}$ \\
\hline $\begin{array}{l}\text { Non-biologic RA DMARDs } \\
\text { received }\end{array}$ & $\begin{array}{l}\text { Yes } \\
\text { No }\end{array}$ & $\begin{array}{l}302(85.6) \\
51(14.4)\end{array}$ & $\begin{array}{l}47(85.5) \\
8(14.5)\end{array}$ & 0.35 \\
\hline Type of non-biological DMARD & $\begin{array}{l}\text { Arava } \\
\text { Methotrexate } \\
\text { Plaquenil } \\
\text { Sulfasalazine } \\
\text { Methotrexate and plaquenil } \\
\text { Methotrexate and Arava } \\
\text { Arava and plaquenil } \\
\text { Sulfasalazine } \\
\text { Cellcept } \\
\text { Plaquenil and sulfasalazine } \\
\text { Sulfasalazine and } \\
\text { Methotrexate }\end{array}$ & $\begin{array}{l}36(11.9) \\
100(33.1) \\
86(28.5) \\
5(1.7) \\
52(17.2) \\
12(4.0) \\
6(2.0) \\
1(0.3) \\
0 \\
1(0.3) \\
2(0.7)\end{array}$ & $\begin{array}{l}6(I 2.8) \\
22(46.8) \\
I I(23.4) \\
I(2 . I) \\
2(4.3) \\
0 \\
3(6.4) \\
0 \\
I(2 . I) \\
I(2 . I) \\
0\end{array}$ & $\begin{array}{c}0.48 \\
0.09 \\
0.87 \\
0.63 \\
0.47 \\
- \\
- \\
- \\
- \\
0.98 \\
-\end{array}$ \\
\hline Use of Steroids for RA & $\begin{array}{l}\text { Yes } \\
\text { No }\end{array}$ & $\begin{array}{l}126(41.7) \\
176(58.3)\end{array}$ & $\begin{array}{l}29(61.7) \\
18(38.3)\end{array}$ & 0.03 \\
\hline OP treatment & $\begin{array}{l}\text { Yes } \\
\text { No } \\
\text { Fosamax } \\
\text { Densukl; mab } \\
\text { Protelos }\end{array}$ & $\begin{array}{l}- \\
- \\
- \\
- \\
-\end{array}$ & $\begin{array}{l}52(94.5) \\
3(5.5) \\
19(36.5) \\
32(61.5) \\
1(1.9)\end{array}$ & - \\
\hline
\end{tabular}

Note: *p-value based on chi-square test or Fisher exact test as appropriate.

Abbreviations: RA, rheumatoid arthritis; OP, osteoporosis; DMARDs, disease modifying anti- rheumatic drugs.

anti-osteoporotic medication, but a lower percentage (36.5\%) received bisphosphonate (Fosamax) (Table 4).

\section{Discussion}

Local and systemic bone loss, in the form of bone erosions and secondary OP respectively, are among the most frequent comorbidities in RA patients. The significant of OP appears to the increased risk of the fragility fracture and thus affecting the individual activity and financially. The main aim of our study was to evaluate the effects of OP on RA disease activity using DAS28-CRP by comparing the outcome between two groups of patients, where RA-OP patients are compared with the reference group of RA-only patients in the same cohort sample. Up to the authors' knowledge, this study is probably one of the first to unveil this area.

Previous studies reported that OP occurs in $30-50 \%$ of RA patients ${ }^{5,6}$ and had strong relation to multiple risk factors that may affect the progression of RA, so that OP commonly found in older patients ${ }^{28}$ and more often female than male, ${ }^{29}$ and had lower BMI, a longer disease duration, ${ }^{30}$ a corticosteroid treatment, ${ }^{7}$ and a higher HAQDI score. ${ }^{7,31}$ Accordingly, among the cohort sample in the current study, we found $13.5 \%$ of treated RA patients developed OP and when compared the demographic data of these patients to RA-only patients, they were significantly older, had longer duration, corticosteroid therapy, 
and a higher HAQ-DI score at 2nd and 3rd clinical visit. Hence these results agreed with previous studies ${ }^{7,28,30,31}$ except for gender and BMI that showed insignificant difference, while the counterintuitive finding related to the percentage of smoking in RA-OP patients was significantly lower than RA-only patients, a result that opposed to literature reports. ${ }^{32}$ We found also, OP commenced in RA patients after a mean duration of $24.6 \pm$ months from the diagnosis of RA that gave a total disease period in RAOP patients of $106.6 \pm 62.6$ months at a mean age of 64.8 \pm 10.8 years, which means the process of bone loss had occurred at an earlier age. This finding was in consistent with previous results by Kleyer et $\mathrm{al}^{33}{ }^{33}$ who proved that bone loss in RA patients with ACPA-positive occurs even before the onset of RA clinical features.

On the other hand, our study did not prove any significant difference in DAS28-CRP scores between RAonly and RA-OP patients during the three clinical visits either by simple statistical comparison or via multivariable regression analysis. Therefore, indicating that OP did not affect the disease activity and the outcome of RA patients, and would not interfere with the management of RA patients. Having examined the association between various risk factors in our data, we did not find any significant association related specifically to the development of OP among RA patients than those who did not have OP except for the age factor that showed the RA-OP group significantly decreased with age compared to patients with RA-only (OR $0.952,95 \%$ CI $0.909-0.997 ; \mathrm{P}=0.036$ ) (Table 1). The reason for this is most probably in our study of RA-OP group, we deal mainly with glucocorticoid induced OP (GIOP), which is a secondary OP, since our statistical analysis revealed the use of glucocorticoid by RA-OP patients was significantly higher than RA-only patients $(61.7 \%$ vs. $41.7 \%, P=0.03)$ (Table 4$)$. This finding is consistent with a comprehensive review done by Sadat-Ali et al, ${ }^{34}$ who reported that secondary OP occurred at a young age group (mean age and SD, 37.4 years) and its prevalence was higher than primary OP both in men and women (46.4 to $31.9, \mathrm{P}<0.001,95 \% \mathrm{CI}<-$ 13.4486). Moreover, the increased relative use ofGCs in RA-OP patients may reflect the increased short term RA activity in this group of patients, and the associated increased risk for occurrence of OP.

Concerning overall principle that we followed in this cohort of patients was treat to target principles regardless the type of DMARDs used to achieve the target. There were no significant differences of various DMARDs received (biologic and non-biologic) between RA-only and RA-OP patients. This entailing that both groups had received and tolerated same medications and there was no difference in their management plan, although most of them having various comorbidities other than $\mathrm{OP}$, the management plan was the same for all RA patients. Following treatment, both groups of RA patients experienced continuing improvement in disease activity, as measured by DAS28-CRP score, and overall, up to $96-97 \%$ patients reach remission and low disease activity after the 2nd clinical visit and continue so to the 3rd clinical visit. Unlike our finding, previous studies on RA patients by Darawankul et $\mathrm{al}^{35}$ and Barnabe et $\mathrm{al}^{36}$ showed lower remission rates at 14.6 and $37 \%$ respectively. In addition, when evaluating the patients' disabilities by HAQ-DI score, we found much improvement in all RA patients' disabilities by the end of the three clinical visits, although there were more significant disabilities with bone loss in RA-OP patients compared to the other group ( $P=0.001$ at 2nd and 3rd visits) (Table 2). These finding were similar to the Hafiz et al report, where HAQ-DI scores tended to increase with increasing radiographic progression of bone loss. ${ }^{37}$

In our cohort study, denosumab was used mostly in conjunction with methotrexate for the treatment of RA-OP patients. This combination has been reported to be beneficial for RA patients with risk factors for joint destruction. ${ }^{38}$ Denosumab was found also useful in combination with DMARDs in suppressing joint destruction and increasing BMD, although it did not affect joint space narrowing or disease activity scores. ${ }^{39}$

There were several limitations to this study. This was a single center study and may not reflect findings of patients treated elsewhere in Saudi Arabia. It was lacking in some data, including the detailed history of smoking, dosing of various DMARDs therapy, duration and dose of GCs, and information about the progression and severity of OP. Moreover, patients in Saudi Arabia have early access to biologic modifiers and DMARDs, which may not be the case in other countries.

In conclusion, the current study revealed that OP has insignificant effects on RA disease activity and thus the development of OP among RA patients will not change the management plan for them. However, we found that the RA-OP group significantly decreased with age compared to patients with RA-only, indicating that this secondary OP might be mostly GIOP, which supported by finding a significant higher consumption of glucocorticoid by RA- 
OP patients. In addition, RA-OP patients had greater disabilities than RA-only patients since the first clinical visit and even though decreased by 2 nd and 3rd visit, disabilities remained significantly higher in RA-OP patients. Hence our recommendation is to focus on aggressive, appropriate and treat to target approach for RA patients regardless of whether they have OP or not to control the RA disease activity. As well as perform early screening for OP and prompt treatment for the newly confirmed RA-OP cases.

\section{Abbreviations}

ACR, American College of Rheumatology; BMI, Body mass index; BMD, Bone mineral density; CKD, Chronic kidney disease; ACPA, Citrullinated proteins antibodies; CRP, C-reactive protein; DM, Diabetes mellitus; Dkk-1, Dickkopf-related protein-1; DMARDs, Disease modifying antirheumatic drugs; DSFH, Doctor Soliman Fakeeh Hospital; DEXA, Dual-energy X-ray absorptiometry; GIOP, Glucocorticoid-induced osteoporosis; GCs, Glucocorticoids; HAQ-DI, Health Assessment Questionnaire-Disability Index; HTN, Hypertension; IFN- $\gamma$, Interferon gamma ; IL-1b, Interleukin -1b; IL-4, Interleukin-4; IL-6, Interleukin-6; IL-11, Interleukin-11; IL-17, Interleukin-17; RANKL, Nuclear factor, kappa-B ligand; OP, Osteoporosis; OPG, Osteoprotegerin; RA, Rheumatoid arthritis; RF, Rheumatoid factor; RASD, Saudi registry of the Rheumatoid Arthritis Saudi Database; SD, Standard deviation; SPSS, Statistical Package for Social science; Th1, T helper cell 1; Th17, T helper cell 17; DAS28-CRP, The Disease Activity Score 28 for Rheumatoid, Arthritis with CRP; TGF- $\beta$, Transforming growth factor- $\beta$; TNF, Tumor necrosis factor; WHO, World health organization.

\section{Acknowledgments}

The research team would like to thank Roaa Alsolaimani for her great contribution in the original data registry of rheumatoid arthritis patients. We would also like to thank Ms. Rugaya Azhar for her great support in data analysis.

\section{Disclosure}

This study was funded by the Alzaidi Chair of Research Chair in Rheumatic Disease, Umm Al Qura University, Makkah, Saudi Arabia. Rheumatoid arthritis Saudi Database (RASD) is a registry designed and funded by Alzaidi Chair and partially funded by Pfizer pharmaceutical. The authors report no other conflicts of interest in this work.

\section{References}

1. Abdulkhaliq A. Bones and rheumatology. In: Almoallim H, Cheikh M, editors. Skills in Rheumatology. Singapore: Springer Singapore; 2021:209-239.

2. Smolen JS, Aletaha D, Barton A, et al. Rheumatoid arthritis. Nat Rev Dis Primers. 2018;4:18001. doi:10.1038/nrdp.2018.1

3. Kanis JA. Diagnosis of osteoporosis and assessment of fracture risk. Lancet. 2002;359(9321):1929-1936. doi:10.1016/S0140-6736(02) 08761-5

4. Almutairi K, Nossent J, Preen D, Keen H, Inderjeeth C. The global prevalence of rheumatoid arthritis: a meta-analysis based on a systematic review. Rheumatol Int. 2021;41(5):863-877. doi:10. 1007/s00296-020-04731-0

5. Haugeberg G, Uhlig T, Falch JA, Halse JI, Kvien TK. Bone mineral density and frequency of osteoporosis in female patients with rheumatoid arthritis: results from 394 patients in the Oslo County Rheumatoid Arthritis register. Arthritis Rheum. 2000;43(3):522-530. doi:10.1002/ 1529-0131(200003)43:3<522::AID-ANR7 >3.0.CO;2-Y

6. Hauser B, Riches PL, Wilson JF, Horne AE, Ralston SH. Prevalence and clinical prediction of osteoporosis in a contemporary cohort of patients with rheumatoid arthritis. Rheumatology. 2014;53 (10):1759-1766. doi:10.1093/rheumatology/keu162

7. Sinigaglia L, Nervetti A, Mela Q, et al. A multicenter cross sectional study on bone mineral density in rheumatoid arthritis. Italian Study Group on Bone Mass in Rheumatoid Arthritis. J Rheumatol. 2000;27 (11):2582-2589.

8. Haugeberg G, Helgetveit KB, Førre Ø, Garen T, Sommerseth H, Prøven A. Generalized bone loss in early rheumatoid arthritis patients followed for ten years in the biologic treatment era. $B M C$ Musculoskelet Disord. 2014;15:289. doi:10.1186/1471-2474-15-289

9. Mori Y, Kuwahara Y, Chiba S, et al. Bone mineral density of postmenopausal women with rheumatoid arthritis depends on disease duration regardless of treatment. J Bone Miner Metab. 2017;35 (1):52-57. doi:10.1007/s00774-015-0716-9

10. Fassio A, Idolazzi L, Jaber MA, et al. The negative bone effects of the disease and of chronic corticosteroid treatment in premenopausal women affected by rheumatoid arthritis. Reumatismo. 2016;68 (2):65-71. doi:10.4081/reumatismo.2016.878

11. Kweon S-M, Sohn DH, Park J-H, et al. Male patients with rheumatoid arthritis have an increased risk of osteoporosis: frequency and risk factors. Medicine. 2018;97(24):e11122-e. doi:10.1097/MD.0000 000000011122

12. Orsolini G, Caimmi C, Viapiana O, et al. Titer-dependent effect of anti-citrullinated protein antibodies on systemic bone mass in rheumatoid arthritis patients. Calcif Tissue Int. 2017;101(1):17-23. doi:10.1007/s00223-017-0253-8

13. Lacey DL, Boyle WJ, Simonet WS, et al. Bench to bedside: elucidation of the OPG-RANK-RANKL pathway and the development of denosumab. Nat Rev Drug Discov. 2012;11(5):401-419. doi:10.1038/ $\operatorname{nrd} 3705$

14. Rossini M, Gatti D, Adami S. Involvement of WNT/ $\beta$-catenin signaling in the treatment of osteoporosis. Calcif Tissue Int. 2013;93 (2):121-132. doi:10.1007/s00223-013-9749-z

15. Lorenzo J, Horowitz M, Choi Y. Osteoimmunology: interactions of the bone and immune system. Endocr Rev. 2008;29(4):403-440.

16. Schett G, Saag KG, Bijlsma JW. From bone biology to clinical outcome: state of the art and future perspectives. Ann Rheum Dis. 2010;69(8):1415-1419. doi:10.1136/ard.2010.135061

17. Diarra D, Stolina M, Polzer K, et al. Dickkopf-1 is a master regulator of joint remodeling. Nat Med. 2007;13(2):156-163. doi:10.1038/ nm1538 
18. Ma Y, Zhang X, Wang M, et al. The serum level of Dickkopf-1 in patients with rheumatoid arthritis: a systematic review and meta-analysis. Int Immunopharmacol. 2018;59:227-232. doi:10.10 16/j.intimp.2018.04.019

19. Terpos E, Fragiadaki K, Konsta M, Bratengeier C, Papatheodorou A, Sfikakis PP. Early effects of IL-6 receptor inhibition on bone homeostasis: a pilot study in women with rheumatoid arthritis. Clin Exp Rheumatol. 2011;29(6):921-925.

20. Dougados M, Soubrier M, Antunez A, et al. Prevalence of comorbidities in rheumatoid arthritis and evaluation of their monitoring: results of an international, cross-sectional study (COMORA). Ann Rheum Dis. 2014;73(1):62-68. doi:10.1136/annrheumdis-2013-204223

21. Richards JS, Cannon GW, Hayden CL, et al. Adherence with bisphosphonate therapy in US veterans with rheumatoid arthritis. Arthritis Care Res. 2012;64(12):1864-1870. doi:10.1002/acr.21777

22. Orgnization WH. WHO Scientific Group on The Assessment Of Osteoporosis At Primary Health Care LeveL. Summary Meeting Report Brussels, Belgium;2004. Available from: https://www.who. int/chp/topics/Osteoporosis.pdf..

23. Briot K, Roux C. Glucocorticoid-induced osteoporosis. RMD Open. 2015;1(1):e000014. doi:10.1136/rmdopen-2014-000014

24. Hoes JN, Bultink IE, Lems WF. Management of osteoporosis in rheumatoid arthritis patients. Expert Opin Pharmacother. 2015;16 (4):559-571. doi:10.1517/14656566.2015.997709

25. Prevoo ML, van 'T Hof MA, Kuper HH, van Leeuwen MA, van de Putte LB, van Riel PL. Modified disease activity scores that include twenty-eight-joint counts. Development and validation in a prospective longitudinal study of patients with rheumatoid arthritis. Arthritis Rheum. 1995;38(1):44-48.

26. Almoallim H, Hassan R, Cheikh M, et al. Rheumatoid Arthritis Saudi Database (RASD): disease Characteristics and Remission Rates in a Tertiary Care Center. Open Access Rheumatol. 2020;12:139-145. doi:10.2147/OARRR.S260426

27. Küçükdeveci AA, Sahin H, Ataman S, Griffiths B, Tennant A. Issues in cross-cultural validity: example from the adaptation, reliability, and validity testing of a Turkish version of the Stanford Health Assessment Questionnaire. Arthritis Rheum. 2004;51(1):14-19. doi:10.1002/art.20091

28. Hooyman JR, Melton LJ 3rd, Nelson AM, O’Fallon WM, Riggs BL. Fractures after rheumatoid arthritis. A population-based study. Arthritis Rheum. 1984;27(12):1353-1361.

29. Gough AKS, Emery P, Holder RL, Lilley J, Eyre S. Generalised bone loss in patients with early rheumatoid arthritis. The Lancet. 1994;344 (8914):23-27. doi:10.1016/S0140-6736(94)91049-9

30. Laan RF, Buijs WC, Verbeek AL, et al. Bone mineral density in patients with recent onset rheumatoid arthritis: influence of disease activity and functional capacity. Ann Rheum Dis. 1993;52(1):21-26. doi:10.1136/ard.52.1.21
31. Cooper C, Coupland C, Mitchell M. Rheumatoid arthritis, corticosteroid therapy and hip fracture. Ann Rheum Dis. 1995;54(1):49-52. doi:10.1136/ard.54.1.49

32. Pouresmaeili F, Kamalidehghan B, Kamarehei M, Goh YM. A comprehensive overview on osteoporosis and its risk factors. Ther Clin Risk Manag. 2018;14:2029-2049. doi:10.2147/TCRM. S138000

33. Kleyer A, Finzel S, Rech J, et al. Bone loss before the clinical onset of rheumatoid arthritis in subjects with anticitrullinated protein antibodies. Ann Rheum Dis. 2014;73(5):854-860. doi:10.1136/ annrheumdis-2012-202958

34. Sadat-Ali M, Al-Habdan IM, Al-Turki HA, Azam MQ. An epidemiological analysis of the incidence of osteoporosis and osteoporosis-related fractures among the Saudi Arabian population. Ann Saudi Med. 2012;32(6):637-641. doi:10.5144/0256-4947.2012.637

35. Darawankul B, Chaiamnuay S, Pakchotanon R, Asavatanabodee P, Narongroeknawin $\mathrm{P}$. The good EULAR response at the first year is strongly predictive of clinical remission in rheumatoid arthritis: results from the TARAC cohort. Clin Rheumatol. 2015;34(1):43-49. doi:10.1007/s10067-014-2749-1

36. Barnabe C, Homik J, Barr SG, Martin L, Maksymowych WP. The effect of different remission definitions on identification of predictors of both point and sustained remission in rheumatoid arthritis treated with anti-TNF therapy. $J$ Rheumatol. 2014;41(8):1607-1613. doi:10.3899/jrheum.131451

37. Hafez EA, Mansour HE, Hamza SH, Moftah SG, Younes TB, Ismail MA. Bone mineral density changes in patients with recent-onset rheumatoid arthritis. Clin Med Insights Arthritis Musculoskelet Disord. 2011;4:87-94. doi:10.4137/CMAMD.S7773

38. Takeuchi T, Tanaka Y, Ishiguro N, et al. Effect of denosumab on Japanese patients with rheumatoid arthritis: a dose-response study of AMG 162 (Denosumab) in patients with Rheumatold arthritis on methotrexate to Validate inhibitory effect on bone Erosion (DRIVE)-a 12-month, multicentre, randomised, double-blind, placebo-controlled, Phase II clinical trial. Ann Rheum Dis. 2016;75 (6):983-990.

39. Takeuchi T, Tanaka Y, Soen S, et al. Effects of the anti-RANKL antibody denosumab on joint structural damage in patients with rheumatoid arthritis treated with conventional synthetic disease-modifying antirheumatic drugs (DESIRABLE study): a randomised, double-blind, placebo-controlled Phase 3 trial. Ann Rheum Dis. 2019;78(7):899-907.
Open Access Rheumatology Research and Reviews is an international, peer-reviewed, open access journal publishing original research, reports, editorials, reviews and commentaries on all aspects of clinical and experimental rheumatology in the clinic and laboratory including the following topics: Pathology, pathophysiology of rheumatological diseases; Investigation, treatment and management of rheumatological diseases; Clinical trials and novel pharmacological approaches for the treatment of rheumatological disorders. The manuscript management system is completely online and includes a very quick and fair peer-review system, which is all easy to use. Visit http://www.dovepress.com/testimonials.php to read real quotes from published authors 